\title{
Study on the Effects Working Overtime on Health and Lifestyle of Tellers of Commercial Banks in Daklak Province
}

\author{
Dung Viet Tran, Dung Van Ha
}

\author{
Banking University HCMC, Vietnam.
}

\begin{abstract}
The paper aims to determine the impact of long working hours on the health and lifestyle of tellers of commercial banks in the province of Daklak. The paper analyzes the system of theoretical basis, refer to the empirical theoretical models of model building and research assumptions. Research processes identified research problems, research objectives to the steps modeling studies, building scale, questionnaire design, collection gathering, processing data analysis, evaluation, and discuss research results. Primary data source collected the direct survey of tellers, conducted by interviewing transactors by detailed questionnaire. A total of studies included in the formal analysis included 321 questionnaires. After standardizing the data, the author used SPSS and AMOS software for analysis. Research results are obtained from quantitative analysis techniques, techniques such as scale reliability testing, EFA discovery factor analysis, CFA affirmative factor analysis, SEM implementation (linear structure). ). The test results of the research hypotheses, 8 research hypotheses of the model are accepted at $95 \%$ confidence, from here will be the basis for the implications and policies to be able to prove overtime work have an impact on the health, lifestyle of bank tellers.
\end{abstract}

Keywords: Overtime, Health, Lifestyle behaviors, Bank tellers.

Article Received: 10 Jan. 2020

Revised: 27 Jan. 2020

Accepted: 18 Feb. 2020

\section{Introduction}

Overtime (OT) is often common in production, business and service activities. Recent studies from a survey of working conditions in European Union countries with a sample size of 21,500 [1] show that $20 \%$ of European workers report very long working hours (more than 45 hours / week). The question is whether there is a relationship between working conditions and employee benefits, how long they work, and how many hours / week they work to gain a good physiological health.

A large proportion of long-working researchers focus on shifting work and too long working weeks [2]. Relatively few people understand the impact of overtime, overtime habits affect workers' health, although the literature shows that long working hours may be related to the risk of overtime. Occupational health and safety $[2,4]$.

The previous studies have shown that the long hours related to psychological health poor [5, 6], the excessive fatigue [7] and the millions evidence of imbalance [8]. Moreover, several studies have shown that prolonged overtime is associated with an imbalance between work and family life, in terms of role actions [9] or fatigue. Fatigue, anxiety and irritability [10].In Vietnam, businesses often use overtime as a way to solve the unexpected increase in workload without having to hire additional labor. Part of the workers wants to work overtime to contribute more products and materials to the economy, to the unit, and to benefit them when they can increase their income. However, working overtime is harmful to workers, business owners and society.

Banking is a financial business that specializes in providing financial and banking services (Deposit, money transfer, loans, payment services, online banking services, etc.) as one of the industries needs to work overtime for workers, especially the role of the tellers. The job of a bank teller requires timely work handling skills, high concentration, high accuracy, good job handling skills and serious work ethics throughout the day. The working time of tellers is often continuous, throughout most of the time working at the Bank, so it will easily cause fatigue, stress and reduce labor productivity. 
In the event that a bank teller has to work overtime regularly, it will cause health consequences, the ability to work out of focus and cause errors when processing transactions with customers, affecting business performance and reputation of the banking industry. The study on the effects of overtime on health and lifestyle behaviors of the tellers of Commercial Banks in Daklak province was conducted to find out the factors affecting health, behavior and the lifestyle of Bank tellers due to frequent overtime work.

Through the results of this study to test theory and study the impact of overtime on health, lifestyle behaviors of bank tellers, thereby contributing to limiting overtime, strengthening measures to take care of health, ensure a better life for Bank tellers and contribute to improving labor productivity as well as morale for tellers, contributing to increasing operational efficiency and profitability for bank tellers Banking industry in Daklak.

\section{Theoretical Basis}

In Western countries, the health consequences of working overtime are the object of interest in many sciences, the topic of workers has always attracted the participation of scientists. Ever. A useful theoretical perspective for studying the relationship between working hours and mental health is the Effort-Recovery model [11]. According to this model, a lot of effort (or work) has a productivity benefit, but it also affects the physiology of the worker in the short term. In principle, these effects or effects are reversible. When regularly working overtime for a long time, the ability to restore the strength of workers in the working process is not guaranteed. In the long term, exposure to high workloads and inadequate recovery can have a negative impact on workers' health. Moreover, the quality of recovery may be poor due to the adverse effects $[12,13,14]$.

In addition, overtime is particularly likely to occur in work overload situations, meaning that the ability to recover physical strength (taking short breaks from work) will also be limited. In the end, inadequate recovery can cause the accumulation of fatigue and ultimately affect health and well-being.

However, there has not been any research work on this issue in Vietnam. Therefore, the research project on the impact of overtime on health and behavior of bank tellers hopes to contribute a part to clarify and prove the theory. Was given by the previous scientists to help realize the role of conditions in the work, while helping workers to be fully aware of working conditions and take positive actions. Extreme in improving yourself and your working environment.

\section{Research Models}

Based on the results of research from theoretical and research institutions, identifying overtime impacts on poor health, and overtime related to employee behaviors, the author proposed the model. Inheritance studies of Taris et al [15]. Are as follows:

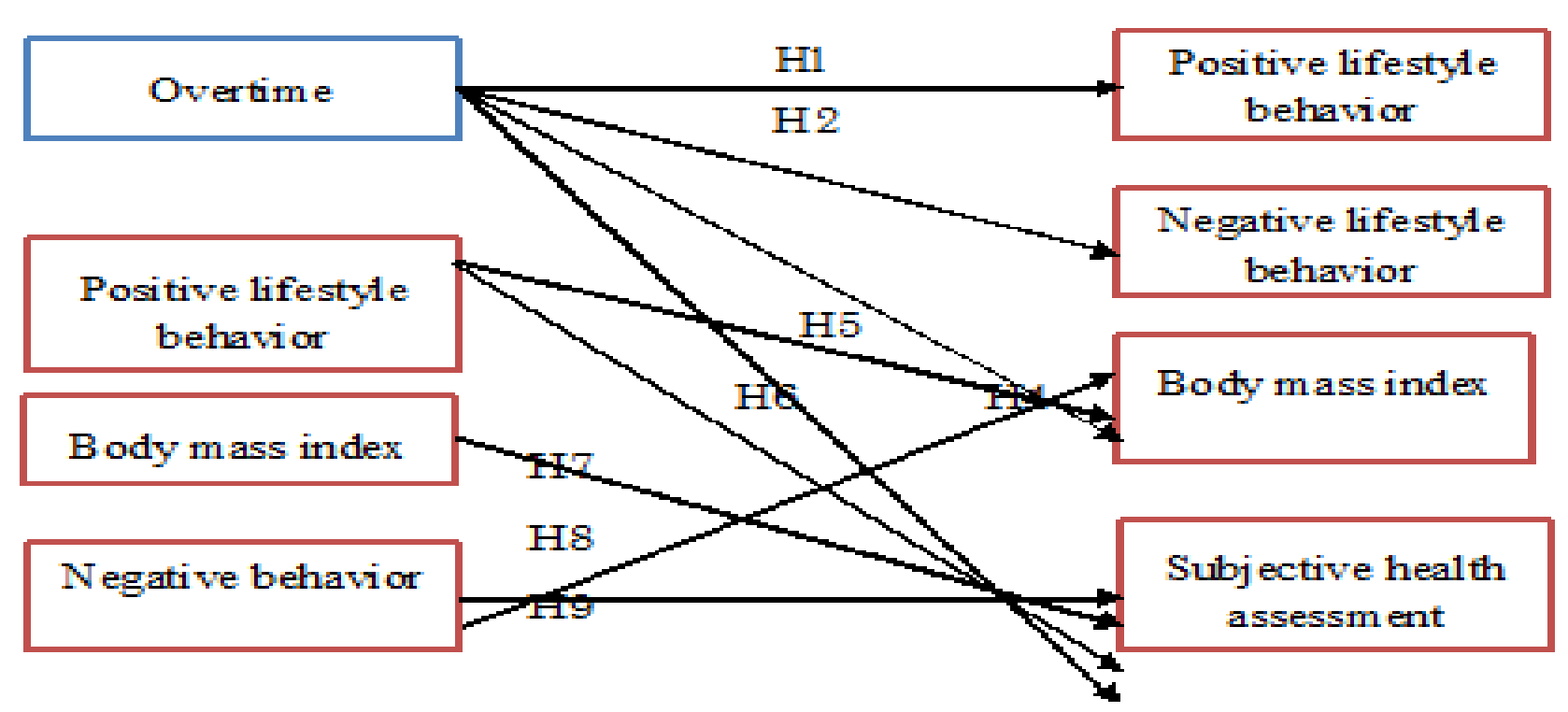

Figure 1: Proposed research model 


\section{Research Hypothesis}

Hypotheses are posed as the impact of overtime on subjective health indicators, body mass index, and lifestyle behaviors.

- H1: Overtime has an opposite effect on positive lifestyle behaviors

- H2: Overtime has a same effect on negative lifestyle behaviors

- H3: Overtime has the same effect on body mass index

- H4: Overtime has an opposite effect on subjective health

- H5: Positive lifestyle behaviors has the same effect on subjective health assessments

- H6: Positive lifestyle behaviors has an opposite effect on body mass index

- H7 : Body mass index has an opposite effect on subjective health

- H8: Negative lifestyle behaviors has the same effect on body mass index

- H9: Negative lifestyle behaviors have an opposite effect on subjective health assessments.

\section{Research Methods}

Researching through books, magazines, domestic and foreign documents, analyzing the theoretical basis system, referring to empirical theoretical models of model building and research hypotheses. The research process goes through many steps from identifying research issues, research objectives to the steps of building a research model, building a scale, designing a questionnaire, collecting, processing and analyzing data, evaluate and discuss research results. The content of the process is shown through the research process diagram as follows:
In order to achieve the goal of the study, the author focuses on determining the factors affecting the health and lifestyle of transactors due to overtime work. Analysis of indicators affecting health: Back pain, joint pain, vision, stomach pain ... about lifestyle behaviors such as exercise habits, diet, nutrition...

Measure the impact of overtime on health, behavior of bank tellers by developing a complete questionnaire and scale. Based on the scale of distributing survey questionnaires to the traders to collect analytical data. Questionnaires are sent to respondents in the form of direct interviews with paper questions. The data was collected from 350 questionnaires, of which 337 were returned, of 337 there were 16 faulty questionnaires and data cleaning, to be included in the official analysis of 321 questionnaires.

And After standardizing the data, the author will use SPSS, AMOS software for analysis. Research results are obtained from quantitative analysis techniques, techniques such as scale reliability testing, EFA discovery factor analysis, CFA affirmative factor analysis, SEM implementation (linear structure). From there, give solutions based on the results that the model offers. In addition, the author proposes a number of solutions to the problems that arise and presents the limitations of the research.

\section{Research Results}

\section{Evaluate the Scale Reliability by Cronback's Alpha Reliability Coefficient}

In order to verify the reliability of the scale, the author has tested the Cronbach's Alpha coefficient, with the number of official research samples obtained as 321 samples; this number of samples is very good for verifying the reliability of the scale through the Cronbach's Alpha coefficient.

Table 1: Summary of Cronbach's Alpha test information

Table 1: Summary of Cronbach's Alpha test information
\begin{tabular}{|c|c|c|c|c|}
\hline Variables & $\begin{array}{c}\text { Scale Mean } \\
\text { if Item } \\
\text { deleted }\end{array}$ & $\begin{array}{c}\text { Scale Variance } \\
\text { of if Item } \\
\text { Deleted }\end{array}$ & $\begin{array}{c}\text { Corrected Item- } \\
\text { Total Correlation }\end{array}$ & $\begin{array}{c}\text { Cronbach's Alpha } \\
\text { if Item deleted }\end{array}$ \\
\hline \multicolumn{7}{|c|}{ Working ovetime concept (OT), Cronbach's Alpha = $\mathbf{0 . 9 1 2}$} \\
\hline LVQG1 & 7.96 & 10.424 & .828 & .772 \\
\hline LVQG2 & 7.98 & 10.468 & .768 & .875 \\
\hline LVQG3 & 8.05 & 11.010 & .830 & .895 \\
\hline LVQG4 & 7.93 & 10.154 & .718 & .874 \\
\hline SKCQ1 & Lack of healthcare concept,Cronbach's Alpha $=\mathbf{0 . 8 7 3}$ & .842 \\
\hline SKCQ2 & 10.99 & 7.925 & .783 & .816 \\
\hline
\end{tabular}




\begin{tabular}{|c|c|c|c|c|}
\hline SKCQ3 & 10.75 & 7.431 & .736 & .834 \\
\hline SKCQ4 & 11.08 & 7.484 & .683 & .857 \\
\hline \multicolumn{5}{|c|}{ Positive health behavior concept, Cronbach's Alpha $=\mathbf{0 . 8 3 4}$} \\
\hline HVSKTC1 & 8.26 & 8.294 & .722 & .766 \\
\hline HVSKTC2 & 8.28 & 7.870 & .818 & .723 \\
\hline HVSKTC3 & 8.17 & 8.159 & .712 & .769 \\
\hline HVSKTC4 & 7.72 & 9.107 & .449 & .891 \\
\hline \multicolumn{5}{|c|}{ Negative health behavior concept (HVSKTUC), Cronbach's Alpha $=\mathbf{0 . 7 7 8}$} \\
\hline HVSKTUC1 & 4.71 & 4.094 & .618 & .703 \\
\hline HVSKTUC2 & 4.37 & 3.379 & .591 & .744 \\
\hline HVSKTUC3 & 4.59 & 3.850 & .655 & .661 \\
\hline \multicolumn{5}{|c|}{ Body mass index concept (CSKCT), cronbach alpha $=\mathbf{0 . 8 9 9}$} \\
\hline CSKCT1 & 4.89 & 4.195 & .799 & .858 \\
\hline CSKCT2 & 4.85 & 4.040 & .850 & .814 \\
\hline CSKCT3 & 5.01 & 4.209 & .756 & .895 \\
\hline
\end{tabular}

Source: Calculation of authors

Through testing the reliability of the preliminary scale, it shows that there are 18 observable variables belonging to 5 concepts that meet the requirements (Cronbach's Alpha value, total correlation coefficient value), 5 research concepts belonging to The research model has a pretty good Cronbach's Alpha value, the lowest is 0.778 and the highest is 0.912 ( $>0.6$ ), so we can say that the scale content of the concepts is quite good, reliable to use. For the study, 18 observed variables will be included for EFA analysis in order to find inconsistent observation variables and once again verify the scale in more detail

\section{Results of EFA Discovery Factor Analysis}

The EFA analysis of the thesis was conducted after the observed variables were tested for the reliability of scales (Cronbach's Alpha), with 18 observed variables after passing the Cronbach's Alpha test, and were included simultaneously to EFA analysis, in order to retest the values of the scale, EFA analysis results are presented as follows:

\section{EFA Analysis}

Using Principal Asix Factoring and Promax to get a tighter data structure to be a prerequisite for further CFA analysis. EFA analysis showed that the coefficient value of
$0.862(>0.5) \mathrm{KMO}$ coefficients is quite good. Besides, Bartlett test value has a Sig value of $0.00<0.05$, so at $95 \%$ confidence, we conclude that the data are suitable for EFA analysis (observed variables are correlated with each other).

Using Principal Axis Factoring factor extraction and Promax matrix rotation data extracted 5 factors at the stop with Eigenvalue factor of $1,318(>1)$, a total extracted variance is $77,969 \%$ ( $>50 \%)$ This means that $77,969 \%$ of the 5 extract factors are explained by 18 observed variables on the scale of 5 concepts, 5 extract factors corresponding to the concepts in the research model.

Table 2: Matrix of factors rotation

\begin{tabular}{|c|c|c|c|c|c|}
\hline \multirow[t]{2}{*}{ Measured variables } & \multicolumn{5}{|c|}{ Factor } \\
\hline & 1 & 2 & 3 & 4 & 5 \\
\hline LVQG1 & .891 & & & & \\
\hline LVQG2 & .770 & & & & \\
\hline LVQG3 & .808 & & & & \\
\hline LVQG4 & .908 & & & & \\
\hline SKCQ1 & & .713 & & & \\
\hline SKCQ2 & & .881 & & & \\
\hline SKCQ3 & & .885 & & & \\
\hline SKCQ4 & & .687 & & & \\
\hline HVSKTC1 & & & & .705 & \\
\hline HVSKTC2 & & & & 1.030 & \\
\hline HVSKTC3 & & & & .810 & \\
\hline HVSKTUC1 & & & & & .753 \\
\hline HVSKTUC2 & & & & & .656 \\
\hline HVSKTUC3 & & & & & .823 \\
\hline CSKCT1 & & & .836 & & \\
\hline CSKCT2 & & & .932 & & \\
\hline CSKCT3 & & & .829 & & \\
\hline
\end{tabular}

Source: Calculation of authors

The observed variables all have factor load factors on which they measure the satisfactory $(>0.5)$, showing that the observed variables of the scale of the corresponding concepts achieve convergence and differentiation factors that it measures. 
Thus, after analyzing the discovery factor of EFA, the number of extracted factors is 5 factors, corresponding to 5 research concepts of the thesis, 18 observed variables are included in the EFA analysis, the results 1 observed variable with factor loading factor on the factor that it measured failed to conduct elimination, the remaining 17 observed variables met the EFA discovery factor analysis, observed variables will be included in further CFA analysis to retest the scale values.

\section{Confirmatory Factor Analysis CFA Result}

Confirmation Factor Analysis CFA (Confirmatory Factor Analysis) is one of the statistical techniques to serve linear structure model, CFA allows us to test how good the measured variables represent factors. CFA is the next step of EFA because CFA is only used appropriately when the researcher has some knowledge of the underlying structure, in which the relationship or hypothesis (derived from theory or experiment) between the measured variables and the baseline factors is assumed by the researcher before conducting statistical testing.

The CFA method is used to reaffirm the unidimensional, reliability, convergent validity and discriminant validity of the scale of factors affecting the health and behavior of bank tellers by working overtime.

\section{Testing the Suitable of CFA Model}

Table 3: Summary of CFA analysis

\begin{tabular}{|l|l|}
\hline The evaluation index & Value \\
\hline CMIN/DF & 1.889 \\
\hline GFI & 0.932 \\
\hline TLI & 0.964 \\
\hline CFI & 0.971 \\
\hline RMSEA & 0.053 \\
\hline Appropriate sig value & 0.000 \\
\hline
\end{tabular}

Source: Calculation of authors

Through the results of assessing the suitability of the CFA analysis, we see the value of $\mathrm{CMIN} / \mathrm{DF}=1,889(<3)$, TLI and CFI, GFI $>0.9$, RMSEA index $0.053<0.08$ and value. sig test of the model $0.000<0.05$ so we can conclude that at $95 \%$ confidence this model is suitable for CFA analysis, the analysis data is compatible with the research model.

\section{Assess the Reliability of the Scale}

The reliability of a scale is one of the values of the scale that need to be tested harder, the reliability through CFA analysis is measured by the general reliability index (CR), total extracted variance ( AVE) and Cronbach's Alpha coefficient.Cronbach's Alpha coefficient above, presented, the scales for the concept of satisfactory Cronbach's Alpha coefficient.

Table 4: Composite reliability, variance extracted

\begin{tabular}{|c|c|c|}
\hline Concept & $\begin{array}{c}\text { Average variance extracted } \\
\text { (AVE) }\end{array}$ & $\begin{array}{c}\text { Composite } \\
\text { Reliability } \\
\text { (CR) }\end{array}$ \\
\hline Working Overtime & 0.912699 & 0.723567 \\
\hline Lack of healthcare & 0.875489 & 0.637964 \\
\hline Body mass index & 0.901098 & 0.753252 \\
\hline Positive health behavior & 0.895694 & 0.741616 \\
\hline Negative health behavior & 0.787131 & 0.55252 \\
\hline
\end{tabular}

Source: Calculation of authors

According to Hair et al [16].The scale is considered to be reliable when the Composite Reliability scores higher than 0.5 and the total average variance extracted is more than 0.5. Based on the evaluation of the total average variance extract and the Composite reliability of the concepts, we see that the scale values seem to value 0.5 and more, for the total average variance extract from 0.787 to 0.912 , the Composite reliability also varies from 0.552 to 0.753 . In summary, the results of the general reliability assessment show that the scales of the research concepts all have satisfactory results, we move on to test other values of the scale. 


\section{Convergent Validity}

According to Hair et al [16].The scale is considered to reach the convergence value when the standardized weights of the scales in CFA analysis are greater than 0.5 and statistically significant. In addition, there is another criterion to test the convergence value is the total average variance extract (AVE) of the concepts must be at a minimum of more than 0.5. According to the analysis, it is shown that all standardized coefficients of the observed variables on the measurement concept have met the requirements (over 0.5). Besides, the total variance extracted from the concepts is also greater than 0.5, from which we can conclude that the factors reach the convergent value (the results are presented in the table of standardized and unstandardized Coefficients).

Table 5: Standardized and unstandardized Coefficients of observed variables

Table 5: Standardized and unstandardized Coefficients of observed variables
\begin{tabular}{|c|c|c|c|c|}
\hline \multicolumn{2}{|c|}{ Correlation between observed variables and concepts } & $\begin{array}{c}\text { Unstandardized } \\
\text { Coefficients }\end{array}$ & $\begin{array}{c}\text { Standardized } \\
\text { Coefficients efficients }\end{array}$ \\
\hline LVQG1 & $<---$ & LVQG & 1.000 & .882 \\
\hline LVQG2 & $<---$ & LVQG & .972 & .822 \\
\hline LVQG3 & $<--$ & LVQG & 1.037 & .813 \\
\hline LVQG4 & $<---$ & LVQG & 1.000 & .883 \\
\hline SKCQ1 & $<---$ & SKCQ & 1.117 & .857 \\
\hline SKCQ2 & $<---$ & SKCQ & 1.107 & .801 \\
\hline SKCQ3 & $<---$ & SKCQ & 1.072 & .747 \\
\hline SKCQ4 & $<---$ & SKCQ & 1.000 & .859 \\
\hline CSKCT1 & $<---$ & CSKCT & 1.100 & .945 \\
\hline CSKCT2 & $<---$ & CSKCT & .951 & .793 \\
\hline CSKCT3 & $<---$ & CSKCT & 1.000 & .812 \\
\hline HVSKTC1 & $<---$ & HVSKTC & 1.125 & .920 \\
\hline HVSKTC2 & $<---$ & HVSKTC & 1.079 & .848 \\
\hline HVSKTC3 & $<---$ & HVSKTC & 1.000 & .740 \\
\hline HVSKTUC1 & $<---$ & HVSKTUC & 1.178 & .706 \\
\hline HVSKTUC2 & $<---$ & HVSKTUC & 1.096 & .782 \\
\hline HVSKTUC3 & $<---$ & HVSKTUC & & \\
\hline
\end{tabular}

Source: Caculation from authors

\section{Homogeneity and Unidimensionality}

Determining the homogeneity and unidimensionality of the scale, based on the values to evaluate the appropriateness of the model, we can conclude that the scale achieves the homogeneity and unidimensionality with the assessment values of a suitable model, CMIN / DF = 1,889 (<3), TLI and CFI evaluation index, GFI $>0.9$, RMSEA index $0.053<0.08$ and sig test value of model $0.000<0.05$ so we can conclude that at the reliability of $95 \%$, this model is suitable for CFA analysis. We can conclude that the scale achieves homogeneity and unidimensionality.

\section{Discriminant Validity}

To test this, discriminant validity is known through the following evaluation criteria:

- Evaluate if the correlation coefficient between factors is far from 1, through correlation coefficient value and $\mathrm{P}$-value test.

- Compare the square root of Total Variance Explained with the correlation coefficients of one factor and the others.

Table 6: Total Variance Explained and its square root

\begin{tabular}{|c|c|c|}
\hline Concept & Averave Variance Extract (AVE) & Square root of AVE \\
\hline Working overtime & 0.912699 & 0.955353 \\
\hline Lack of healthcare & 0.875489 & 0.935676 \\
\hline Body mass index & 0.901098 & 0.949262 \\
\hline Positive health behavior & 0.895694 & 0.946411 \\
\hline Negative health behavior & 0.787131 & 0.887204 \\
\hline
\end{tabular}


Table 7: Discriminant validity test

\begin{tabular}{|l|l|l|l|l|l|l|}
\hline \multicolumn{2}{|l|}{ Correlation between concepst } & Estimate & S.E & C.R & P \\
\hline LVQG & $<-->$ & SKCQ & -.285 & .055 & -5.151 & $* * *$ \\
\hline LVQG & $<->$ & CSKCT & .359 & .064 & 5.586 & $* * *$ \\
\hline LVQG & $<->$ & HVSKTC & -.430 & .067 & -6.422 & $* * *$ \\
\hline LVQG & $<->$ & HVSKTUC & .385 & .060 & 6.464 & $* * *$ \\
\hline SKCQ & $<-->$ & CSKCT & -.286 & .050 & -5.677 & $* * *$ \\
\hline SKCQ & $<->$ & HVSKTC & .245 & .049 & 5.022 & $* * *$ \\
\hline SKCQ & $<->$ & HVSKTUC & -.255 & .046 & -5.519 & $* * *$ \\
\hline CSKCT & $<->>$ & HVSKTC & -.265 & .055 & -4.854 & $* * *$ \\
\hline CSKCT & $<->$ & HVSKTUC & .254 & .050 & 5.085 & $* * *$ \\
\hline HVSKTC & $<->>$ & HVSKTUC & -.221 & .048 & -4.563 & $* * *$ \\
\hline S
\end{tabular}

Source: Caculation from authors

Based on the research results, we find that the square root of the total variance extracted and the correlation coefficients satisfy the condition, so we can say that with existing data, the scale achieves the discriminant validity.
This shows that the research scale is very reliable and well used. Thus, through confirmatory factor analysis, we get the CFA model shown in the figure, with criteria to evaluate the model's suitability to be met, or the values of the scale are also meet and satisfy the request.

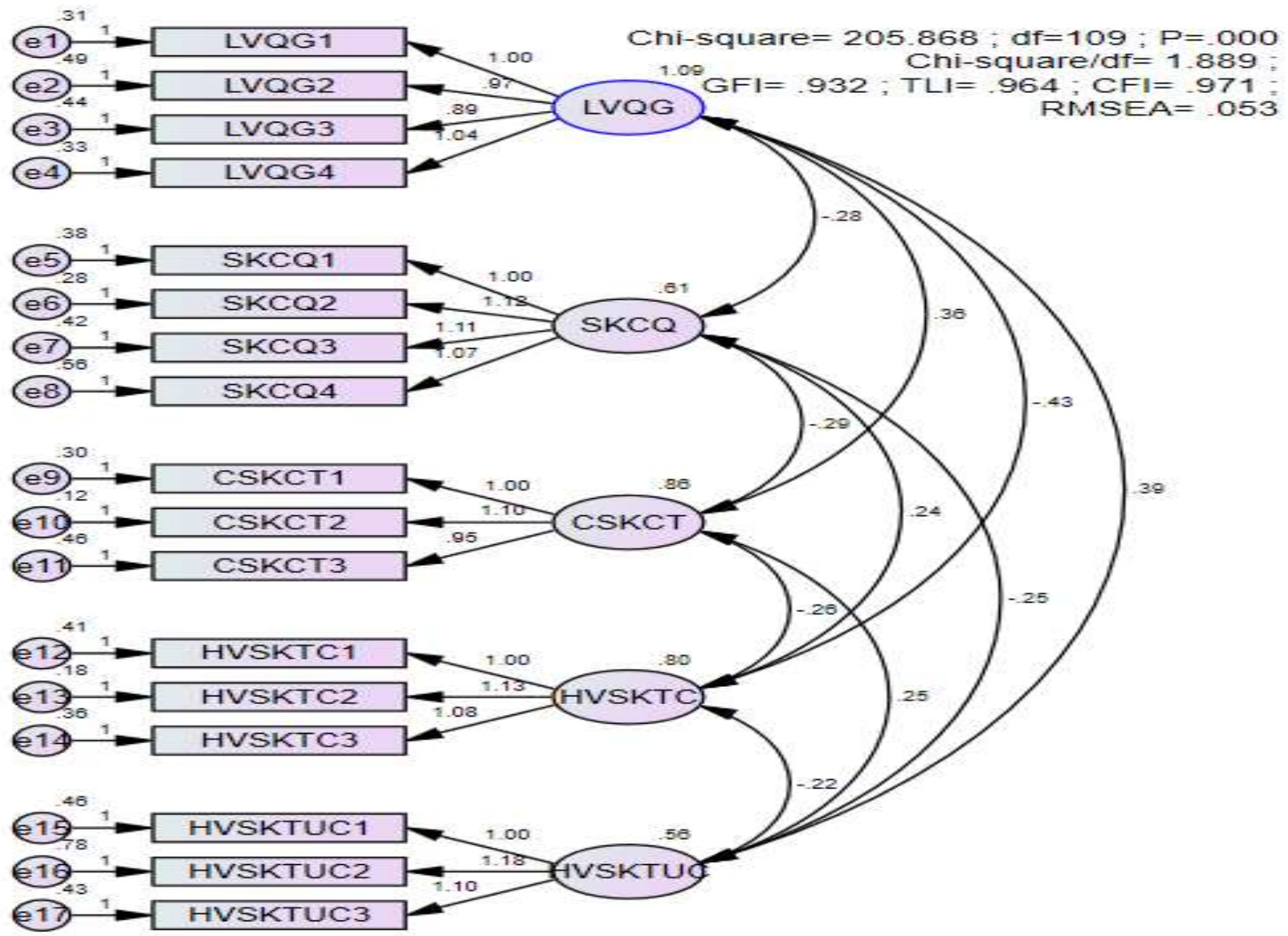

Figure 2: CFA model result

Source: Caculation from authors

\section{Structural Equation Modeling (SEM)}

After conducting the CFA confirmatory factor analysis, we conducted an analysis of the structural equation modeling SEM, in order to test the research hypotheses and measure the impact of the factors on each other.
The SEM method shows advantages over multiple linear regression method since it solves the simultaneous estimation model, complex relationships will be expressed easily hence, no partial regression is required to calculate the overall model fit later. 
Dung Viet Tran | International Journal of Advances in Management and Economics | 2020| Vol. 09| Issue 02| 32-43

Table 8: Structural equation modeling SEM result

\begin{tabular}{|c|c|c|c|c|c|c|c|}
\hline & & & Estimate & S.E. & C.R. & P & Label \\
\hline HVSKTC & $<---$ & LVQG & -.398 & .053 & -7.464 & $* * *$ & \\
\hline HVSKTUC & $<---$ & LVQG & .359 & .048 & 7.560 & $* * *$ & \\
\hline CSKCT & $<---$ & LVQG & .165 & .066 & 2.496 & .013 & \\
\hline CSKCT & $<---$ & HVSKTC & -.173 & .067 & -2.571 & .010 & \\
\hline CSKCT & $<---$ & HVSKTUC & .274 & .090 & 3.028 & .002 & \\
\hline SKCQ & $<---$ & LVQG & -.039 & .055 & -.700 & .484 & \\
\hline SKCQ & $<---$ & HVSKTC & .151 & .058 & 2.614 & .009 & \\
\hline SKCQ & $<--$ & CSKCT & -.187 & .054 & -3.492 & $* * *$ & \\
\hline SKCQ & $<---$ & HVSKTUC & -.287 & .080 & -3.603 & $* * *$ & \\
\hline
\end{tabular}

Source: Caculation from authors

Table 9: Boostrap analysis

\begin{tabular}{|l|l|l|l|l|l|l|l|}
\hline \multicolumn{2}{|l|}{ Parameter } & SE & SE-SE & Mean & Bias & SE-Bias \\
\hline HVSKTC & $<--$ & LVQG & .067 & .002 & -.392 & .006 & .003 \\
\hline HVSKTUC & $<---$ & LVQG & .049 & .002 & .358 & -.001 & .002 \\
\hline CSKCT & $<---$ & LVQG & .069 & .002 & .163 & -.001 & .003 \\
\hline CSKCT & $<---$ & HVSKTC & .072 & .002 & -.174 & -.001 & .003 \\
\hline CSKCT & $<---$ & HVSKTUC & .108 & .003 & .272 & -.002 & .005 \\
\hline SKCQ & $<---$ & LVQG & .064 & .002 & -.037 & .001 & .003 \\
\hline SKCQ & $<---$ & HVSKTC & .071 & .002 & .151 & .001 & .003 \\
\hline SKCQ & $<---$ & CSKCT & .067 & .002 & -.188 & -.001 & .003 \\
\hline SKCQ & $<---$ & HVSKTUC & .101 & .003 & -.291 & -.004 & .005 \\
\hline
\end{tabular}

Source: Caculation from authors

Boostrap analysis results, with 350 research samples conducted by Boostrap help reassess the estimation model, with the analysis results showing that the average of the estimated coefficients is not different from the conventional estimation method. Besides, the estimated errors between the two methods are not significant, so we can conclude that the estimated coefficients of the model are reliable and the interpretation of results is safe.

- Through the verification table of research hypotheses, we see that the impact of working overtime on positive lifestyle behaviors is -0.398 , with test significance of sig $=0.000(<0.05)$, hence at reliability level of $95 \%$, we can conclude that Working overtime has a negative effect on positive lifestyle behaviors, increasing overtime will reduce positive lifestyle behaviors and vice versa.

- The impact of Working overtime on negative behavioral behaviors is 0.359 , with sig value of 0.000 much less than 0.05 , so at $95 \%$ reliability level we conclude that Working overtime has a positive effect to negative lifestyle behaviors. This means, in the same conditions, increasing overtime by
1 unit will decrease the negative lifestyle by to 0.359 units and vice versa.

- The impact of Working overtime on body mass index is 0.165 , with sig value of 0.003 $(<0.05)$ so at a $95 \%$ reliability level we conclude that Working overtime has to affect accordingly to the body mass index. In the same conditions, the more overtime it is the more volatile the body mass index is.

- The impact of Working overtime on Lack of healthcare is -0.039 with a test value of $0.484>0.05$, hence at $95 \%$ reliability level, we conclude that Working overtime has no negative effect on lack of healthcare.

- The impact coefficient of positive lifestyle behaviors on Lack of healthcare is 0.151 and the test value is $0.009(<0.05)$, hence at a $95 \%$ reliability level, we conclude that Positive lifestyle behaviors have a positive impact on lack of healthcare.

- The impact coefficient of positive lifestyle behaviors on body mass index is -0.173 and a test value of $0.010(<0.05)$, hence at $95 \%$ reliability level, we can conclude that Positive lifestyle has a negative effect on body mass index 
- The impact coefficient of body mass index on subjective health is -0.187 and the test value is $0.000<0.05$, hence at $95 \%$ reliability level, we can conclude that the Body Mass Index have a negative effect on Lack of healthcare

- The impact coefficient of Negative lifestyle behaviors impact on body mass index is 0.274 and a test value of $0.002<0.05$, hence at $95 \%$ reliability level, we can conclude that Negative lifestyle behaviors have a positive effect on body mass index

- The impact coefficient of negative lifestyle behaviors on subjective health is -0.287 with a test value of $0.000(<0.05)$, hence at $95 \%$ reliability level, we can conclude that Negative lifestyle behaviors have negative effect on Lack of healthcare.
- The impact coefficient of positive lifestyle behaviors on body mass index is -0.173 and a test value of $0.010(<0.05)$, hence at $95 \%$ reliability level, we can conclude that positive lifestyle has a negative effect on body mass index

Thus, the test results of research hypotheses show us 8 research hypotheses of the model are accepted at the $95 \%$ reliability level, which will be the basis for the implications and policies to prove that proving that working overtime affects the health and behavior of bank tellers.

Through Structural equation modeling SEM, the main criteria to evaluate the suitability of the model are shown as follows:

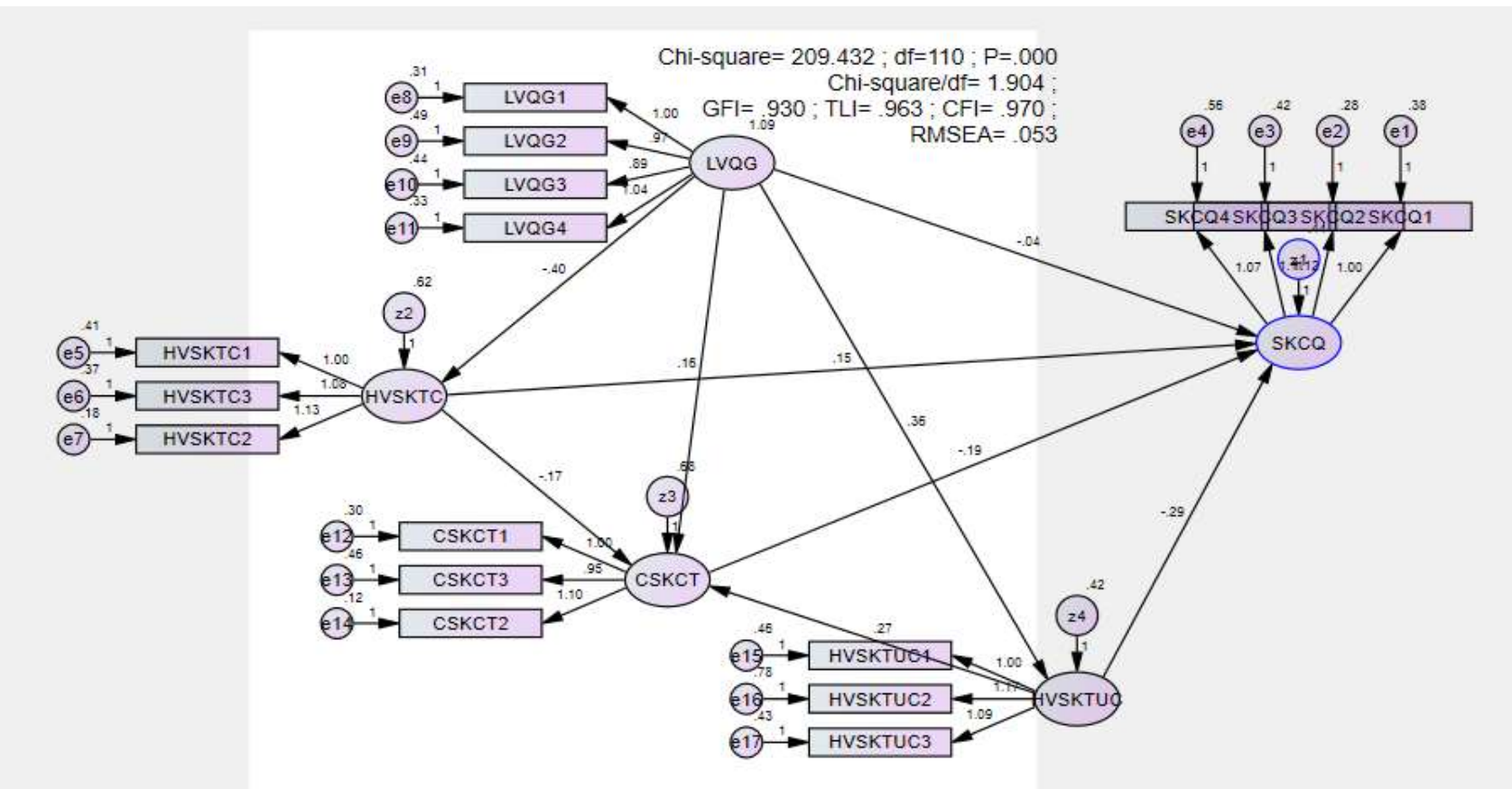

Figure 2: Structural equation modeling result Source: Caculation from authors

\section{Conclusions and Policy Implications}

\section{Conclusion}

With the aim of determining the impact of working overtime on the health and lifestyle behavior of tellers of commercial banks in Daklak province, the research has conducted basic steps such as building theoretical models and research hypotheses. The process goes through many steps from identifying issues and objectives to building a model, a scale, designing a questionnaire, collecting, processing and analyzing data, evaluating and discussing results. The primary data source is collected by a direct survey of tellers, conducted by interviewing traders with a detailed questionnaire. The sample for official analysis has 321 questionnaires and after standardizing the data, the author will use SPSS and AMOS software for analysis. Results are obtained from quantitative analysis techniques such as scale reliability testing, EFA discovery factor analysis, CFA confirmative factor analysis, SEM). As a result, 1 out of 18 measured variables was removed from the scale, 8 out of 9 proposed research hypotheses was accepted. 
Table 10: Results of research hypotheses

\begin{tabular}{|c|c|}
\hline Hypotheses & Result \\
\hline H1: Working overtime has a negative effect on positive lifestyle behaviors & Accepted \\
\hline H2: Working overtime has a positive effect on negative lifestyle behaviors & Accepted \\
\hline H3: Working overtime has a positive effect on body mass index & Accepted \\
\hline H4: Working overtime has a negative effect on Lack of healthcare & Refuse \\
\hline H5: Positive lifestyle behaviors have the same effect on subjective health assessments & Accepted \\
\hline H6: Positive lifestyle behaviors have the negative effect on body mass index & Accepted \\
\hline H7: Body mass index has a negative effect on lack of health & Accepted \\
\hline H9: Negative lifestyle behaviors have a positive effect on body mass index & Accepted \\
\hline
\end{tabular}

Source: Statistics from authors

\section{Policy Implications}

Bank managers in DakLak province need to pay attention to tellers' health and arrange for them to be compensatory leave off and take turns to allow proper to recreation and recuperation. At the same time, reward officials and employees, especially the transactors whose achievements deserve recognition, there should be a way to evaluate the performance closely and objectively to promptly recognize and reward for the effort that the tellers have made. Besides paying salaries, it is necessary to ensure a stable source of income.

Meantime, the value of a valuable reward must be materially helpful for the tellers so that they are motivated to work, hence having a way to evaluate the results of performance fairly and objectively so that tellers feel rewards are always appropriate and fair. Based on the results, positive lifestyle behaviors have a good impact on the lack of healthcare with an impact coefficient of 0.151 and vice versa, therefore, the management of Banks in the area need to pay more attention to the life of the tellers at a higher level to encourage them to lead a positive lifestyle a better state of health, often tellers to take exercises, hold physical competitions that advocate for good health and a healthier lifestyle.

Results show that working overtime has a negative effect on positive lifestyle behaviors (-0.398), working overtime has a positive effect on negative lifestyle behaviors (0.359) and working overtime has a positive effect on body mass index (0.165), which show that working overtime actually has a great impact on various factors to be considered, means the more you work overtime the more active lifestyle behaviors will diminish. In other words, overtime will be negatively correlated with positive lifestyles, which leads to the possibility of health deterioration, the management needs to bear in mind this situation of tellers.
It is necessary to arrange working hours in a balanced and reasonable way, take regular consideration of the lifestyle of tellers, as a result, having a reward scheme or raise income to stimulate enthusiasm and ensure the material wealth without overtime pressure to work for material compensation. Banks can implement welfare policies that make tellers feel that material rewards are worthwhile and safe for their lives so that they reduce the overtime pressure.

Moving on, results show that positive lifestyle behaviors have a positive effect on subjective health assessment (0.151), positive lifestyle behaviors have the negative effect on body mass index (-0.173), body mass index has a negative effect on subjective health (0.187), negative lifestyle behaviors have the same positive effect on body mass index (0.274), negative lifestyle behaviors have a negative effect on lack of healthcare (-0.287).

Therefore, the results also show that the more positive the lifestyle, the better the health of the tellers and the better the body mass index, so the management needs to take active lifestyle of the tellers towards better health during the working process, plan to arrange take-turn leave off enabling them to rest, recover and refresh so that they are healthy enough to stay longer with the organization.

Need to organize and promote the health care activities for tellers, help them to have a positive daily life through health care policies, need to create promotion opportunities for qualified tellers by giving chances to develop professional skills for tellers who are capable of and potential enough with a good performance so that they can feel the favor of organizations agencies and that development pathways are favorable, hence, they are more likely to lead a healthier and active lifestyle. Preferential policies for qualified tellers must ensure 
fairness, objectivity and these individuals must understand the incentives that the organization gives so that they can be assured of the path of promotion and development to be motivated to work and to train themselves better, creating promotion opportunities must be associated with personal achievements, those who strive and achieve good results are absolutely must be guaranteed to implement the policy of selfdevelopment in order to help tellers lead a more active and productive life at work. Policies can be implemented such as propagating the overall goals of the divisions to relevant officials and employees. Hence, they can better understand their objectives in a real context.

The job will now have a better understanding of its job goal. In addition, Banks need to arrange a suitable workload so that tellers can make good use of their skills and expertise to help them see that expertise is necessary and practical for the job. At the same time, consider the job characteristics when assigning work to officials and employees which should be in accordance with their capacity to ensure there is a between the goals and job characteristics. Maintaining the job goals that the unit has done well means continue to let tellers decide on work-related issues so they can be more autonomous at work. This leads to more effective working policies [17-33].

\section{References}

1. Merllié D (2000) Ten years of working conditions in the European Union. Luxembourg, Office for Official Publications of the European Communities/European Foundation for the Improvement of Living and Working Conditions, 7.

2. Thierry H, Meijman T (1994) Time and behavior at work.

3. Harrington JM (1994) Working long hours and health.

4. Spurgeon A, Harrington JM, Cooper CL (1997) Health and safety problems associated with long working hours: a review of the current position. Occupational and environmental medicine, 54(6): 367-375.

5. Sparks K, Cooper C, Fried Y, Shirom A (1997) The effects of hours of work on health: a meta-analytic review. Journal of occupational and organizational psychology, 70(4): 391-408.

6. Borg V, Kristensen TS (1999) Psychosocial work environment and mental health among travelling salespeople. Work \& Stress, 13(2): 132-143.

7. Rosa RR (1995). Extended workshifts and excessive fatigue. Journal of Sleep Research, 4: 51-56.

8. Barnett RC, Gareis KC, Brennan RT (1999) Fit as a mediator of the relationship between work hours and burnout. Journal of occupational health psychology, 4(4): 307.

9. Staines GL, Pleck JH (1984) Nonstandard work schedules and family life. Journal of Applied Psychology, 69(3): 515.

10. Grzywacz JG, Marks NF (2000) Reconceptualizing the work-family interface: An ecological perspective on the correlates of positive and negative spillover between work and family. Journal of occupational health psychology, 5(1): 111.

11. Meijman TF, Mulder G, Drenth PJ, Thierry H, De Wolff CJ (1998) Handbook of work and organizational psychology. Work psychology, 2.

12. Repetti RL (1989) Effects of daily workload on subsequent behavior during marital interaction: The roles of social withdrawal and spouse support. Journal of personality and social psychology, 57(4): 651.

13. Repetti RL (1993) Short-term effects of occupational stressors on daily mood and health complaints. Health Psychology, 12(2): 125.

14. Chan CJ, Margolin G (1994) The relationship between dual-earner couples' daily work mood and home affect. Journal of Social and Personal Relationships, 11(4): 573-586.

15. Taris TW, Ybema JF, Beckers DG, Verheijden MW, Geurts SA, Kompier MA (2011) Investigating the associations among overtime work, health behaviors, and health: a longitudinal study among full-time employees. International journal of behavioral medicine, 18(4): 352-360.

16. Hair JF, Anderson RE, Tatham RL, Black WC (1995) Multivariate data analyses with readings. Englewood Cliffs, New Jersey. 
17. Culyer AJ (1976) Need and the National Health Service: economics and social choice. Rowman \& Littlefield Publishers.

18. Culyer AJ, Wagstaff A (1993) Equity and equality in health and health care. Journal of health economics, 12(4): 431-457.

19. Hatcher L (1994) A step-by-step approach to using the $\mathrm{SAS}(\mathrm{R})$ system for factor analysis and structural equation modeling. Cary, NC: SAS Institute.

20. Hoang Trong, Chu Nguyen Mong Ngoc (2008) Research data analysis with SPSS 1-2, Hong Duc Publisher.

21. Kleppa E, Sanne B, Tell GS (2008) Working overtime is associated with anxiety and depression: the Hordaland Health Study. Journal of occupational and environmental medicine, 50(6): 658-666.

22. Lalonde M (1974) A New Perspective on the Health of Canadians: A Working Document $=$ Nouvelle Perspective De La Sante Des Canadiens.

23. Liu Y, Tanaka H (2002) Overtime work, insufficient sleep, and risk of non-fatal acute myocardial infarction in Japanese men. Occupational and Environmental Medicine, 59(7): 447-451.

24. Lynch JW, Kaplan GA, Cohen RD, Tuomilehto J, Salonen JT (1996) Do cardiovascular risk factors explain the relation between socioeconomic status, risk of all-cause mortality, cardiovascular mortality, and acute myocardial infarction?. American journal of epidemiology, 144(10): 934-942.

25. Maslow AH (1943) A theory of human motivation. Psychological review, 50(4): 370.

26. Nakamura K, Shimai S, Kikuchi S, Takahashi H, Tanaka M, Nakano S, Yamamoto M (1998) Increases in body mass index and waist circumference as outcomes of working overtime. Occupational Medicine, 48(3): 169-173.
27. Nguyen Dinh Tho (2011) "Methods of scientific research in business". Social Labor Publisher, HCMC.

28. Nutbeam D, Harris E, Wise W (2010) Theory in a nutshell: a practical guide to health promotion theories. McGraw-Hill.

29. Park J, Kim Y, Cho Y, Woo KH, Chung HK, Iwasaki K, Hisanaga N (2001) Regular overtime and cardiovascular functions. Industrial health, 39(3):244-249.

30. Steptoe A, Wardle J, Lipsey Z, Mills R, Oliver G, Jarvis M, Kirschbaum C (1998) A longitudinal study of work load and variations in psychological well-being, cortisol, smoking, and alcohol consumption. Annals of Behavioral Medicine, 20(2): 84-91.

31. Thomas HR (1992) Effects of scheduled overtime on labor productivity. Journal of Construction Engineering and Management, 118(1), 60-76.Virtanen Marianna. Overtime work and incident coronary heart disease: the Whitehall II prospective cohort study. European Heart Journal, 31(14):1737-1744 · May 2010.

32. Van Der Hulst M, Geurts S (2001) Associations between overtime and psychological health in high and low reward jobs. Work and Stress, 15(3): 227240.

33. Virtanen M, Ferrie JE, Singh-Manoux A, Shipley MJ, Vahtera J, Marmot MG, Kivimäki M (2010) Overtime work and incident coronary heart disease: the Whitehall II prospective cohort study. European Heart Journal, 31(14): 1737-1744. 